\title{
Serum and Urine Interleukin-6 and Interleukin-8 Levels Do Not Differentiate Acute Pyelonephritis from Lower Urinary Tract Infections in Children
}

\author{
This article was published in the following Dove Press journal: \\ Journal of Inflammation Research
}

\author{
Maysoun Al Rushood (D) \\ Amal AL-Eisa' \\ Rajaa' AL-Attiyah (iD) ${ }^{2}$ \\ 'Department of Pediatrics, Faculty of \\ Medicine, Health Sciences Center, Kuwait \\ University, Kuwait City, Kuwait; \\ ${ }^{2}$ Department of Microbiology, Faculty of \\ Medicine, Health Sciences Center, Kuwait \\ University, Kuwait City, Kuwait
}

Background: Urinary tract infection (UTI) is common in pediatrics. Infection of the upper urinary tract may cause renal scarring, and subsequently renal failure and hypertension. Permanent renal damage has been suggested to be caused by the host inflammatory response. Therefore, it is crucial to understand the host defense mechanisms against such infection in order to make timely diagnosis. The aim of this study was to evaluate interleukin-6 (IL-6) and IL-8 as potential biomarkers in differentiating acute pyelonephritis (AP) from cystitis (Cys) in children. Methods: Forty-three children (21 with AP and 22 with Cys) were included. Serum and urinary IL-6 and IL-8 were measured during the acute phase (within 12 hours of presentation) and the convalescent phase ( 8 weeks post-infection). Thirty-eight healthy children were included as controls.

Results: During the acute phase, the mean urinary IL-6 level in the Cys group was significantly higher than that in the controls $(17.8 \mathrm{pg} / \mathrm{mL}$ vs $14.8 \mathrm{pg} / \mathrm{mL}, \mathrm{P}=0.03)$, while the serum levels were significantly higher in both the Cys and AP groups than in the controls (19.5 pg/mL, $19.4 \mathrm{pg} / \mathrm{mL}, 15 \mathrm{pg} / \mathrm{mL}, \mathrm{P}=0.005$ and 0.02 , respectively). During the convalescent phase, serum and urinary IL-6 levels were higher in patients than in controls. Urinary IL-8 levels were significantly higher in both the AP and Cys groups compared to controls (206.5 pg/mL, $291.8 \mathrm{pg} / \mathrm{mL}, 89.4 \mathrm{pg} / \mathrm{mL}, \mathrm{P}=0.05$ and 0.02 , respectively) during the acute phase. Serum IL-8 was not significantly different between the 3 groups. Nonetheless, no significant differences were found between the AP and Cys groups, in urinary or serum levels of IL-6 or IL-8, during both phases.

Conclusion: IL- 6 and IL-8 levels are elevated in patients with UTI. However, the levels did not differentiate between AP and cystitis. Further studies are warranted to evaluate their roles as indicators of the site of UTIs.

Keywords: cystitis, IL-6, IL-8, pyelonephritis, UTI
Correspondence: Maysoun Al Rushood Department of Pediatrics, Faculty of Medicine, Kuwait University, P.O. Box 24923, Safat 13110, Kuwait City, Kuwait Tel +965-25319486

Fax +965-25338940

Email maysounrushood@hsc.edu.kw

\section{Introduction}

Urinary tract infection (UTI) is common in pediatrics as it constitutes a significant percentage of hospital admissions. It occurs in $1.1 \%$ of girls and $1.4 \%$ of boys in the first year of life. ${ }^{1}$ Infection of the upper urinary tract may cause renal damage, scarring and subsequently renal failure and hypertension.,3 Permanent renal damage has been suggested to be caused by the host inflammatory response to the invading organism with ischemic reperfusion injury. ${ }^{2}$ Therefore, it is crucial to understand the pathogenesis of UTIs and the host defense mechanisms against such an infection. 
The inflammatory response of the host involves the release of a set of proinflammatory cytokines that enhance the inflammatory process.

Interleukin-6 (IL-6) and interleukin-8 (IL-8) are produced in response to bacterial infections and are important mediators of inflammation. ${ }^{2}$

IL-6 is a multifunctional cytokine that regulates numerous body functions, such as the acute phase response, inflammation and organ development. The IL-6 receptor, to which IL-6 binds directly, is expressed by macrophages, neutrophils, T-helper cells, hepatocytes and podocytes. There is also a soluble IL-6 receptor, which, due to its ubiquitous expression, allows IL-6 to modulate a broad spectrum of target cells. ${ }^{4}$

On the other hand, IL-8 is a chemokine produced by macrophages in response to tumor necrosis factor- $\alpha$ (TNF$\alpha$ ), IL-1 and IL-2. It is a major attractant to neutrophils. ${ }^{1,2}$

Both IL- 6 and IL- 8 are present in trace amounts in the urine of healthy subjects. ${ }^{3}$ Therefore, urinary levels of IL6 and IL- 8 are thought to be biomarkers of UTI and most likely the site of infection in the urinary tract.

Many studies have reported that urinary and serum IL6 and IL-8 levels are elevated in UTI. ${ }^{1-3,5-10}$ However, the results are conflicting regarding their role as biomarkers for the site of the infection.

The aim of this case-control study is to evaluate the role of both urinary and serum IL-6 and IL- 8 levels as potential bioindicators of the site infection in the urinary tract in children.

\section{Methods}

A total of 43 children diagnosed with urinary tract infection were included in the study. All patients were either admitted to the pediatric department at Mubarak AL-Kabir Hospital, the main teaching hospital, or seen in the emergency room, between Jan/2017 to Jan/2019. Acute pyelonephritis was diagnosed in 22 patients, and acute cystitis was diagnosed in 21 patients. Diagnosis of acute pyelonephritis was based on the presence of a positive urine culture $\left(>/=5 \times 10^{4}\right.$ colony forming units $(\mathrm{CFU}) / \mathrm{mL}$ of a single pathogenic organism in urine samples obtained by transurethral catheterization or $>/=100,000 \mathrm{CFU} \mathrm{CFU} / \mathrm{mL}$ in a midstream urine or clean catch sample or any count in a suprapubic aspiration sample) in the context of fever (body temperature $>38^{\circ} \mathrm{C}$ ), flank pain, leukocytosis, positive C-reactive protein (CRP), and high erythrocyte sedimentation rate (ESR) and was confirmed by a positive 99 Tc-dimercaptosuccinic acid scintigraphy (DMSA) result.
Cystitis was diagnosed by the presence of bacteriuria, defined as the growth of $>=50,000 \mathrm{CFU} / \mathrm{mL}$ of a single pathogenic organism in a catheterized sample or 100,000 $\mathrm{CFU} / \mathrm{mL}$ in a midstream/clean catch sample or any count in a suprapubic aspiration sample, with symptoms suggestive of bladder irritation (urgency, frequency, suprapubic pain, dysuria) in the absence of signs and symptoms of systemic toxicity, such as fever, chills and rigors. Patients who lost follow-up or had missing data were excluded from the study; other exclusion criteria were children with recurrent UTI, children known or diagnosed with UTI risk factors, such as congenital renal anomalies, anatomical malformation, renal calculi susceptibility, VUR, bladder and bowel dysfunction, neurogenic bladder, indwelling or intermittent catheterization, immunodeficiency, or sepsis.

Initially, the aim was to recruit 100 patients (50 with AP and 50 with cystitis). Samples of the acute phase were collected, but unfortunately, many did not come for follow-up. Therefore, convalescent phase samples were collected in $22 \mathrm{AP}$ and 21 cys patients only.

Thirty-eight healthy children of similar ages and ethnic backgrounds were included as controls. The control subjects were recruited from the general pediatrics OPD. They were healthy children with no history of UTI, who came for regular follow-up with their general pediatricians. All were interviewed to exclude history of UTI or renal disease. All controls had urine routine, microscopy and culture as well as renal profile to exclude the presence of urinary tract infection or any underlying renal derangement.

Blood and urine samples for IL-6 and IL-8 assays were collected from all patients during the first 12 hours of presentation and 8 weeks post-infection. The convalescent samples were collected at 8 weeks because it is enough time to make sure that the infection has cleared, and all acute phase reactants and cytokines are back to baseline levels. We chose not to wait longer as the patients might get another infection during this time and might not be able to collect convalescent samples.

Leucocyte count (WBC) in blood as well as other acute phase reactants, including CRP and ESR, were assessed in all patients with urinary tract infections. Renal US was performed to all patients (Cys and AP). DMSA scan was performed for AP patients on presentation and repeated after 6 months for those who had a positive scan at presentation to look for evidence of scarring.

The study was approved by the Health Science Center Ethics Committee for the protection of human subjects in research, Kuwait University. The study was conducted in 
accordance with the Declaration of Helsinki. Informed consent was obtained from caregivers of all patients and controls.

\section{Cytokine Assay}

Blood and freshly voided urine samples were collected and centrifuged at $1500 \mathrm{rpm}$ at $4^{\circ} \mathrm{C}$ for 20 minutes. The supernatant was then collected, aliquoted, and immediately frozen at $-80^{\circ} \mathrm{C}$ until assessment. After centrifugation of the blood samples at $4^{\circ} \mathrm{C}$, separated plasma samples were aliquoted and stored at $-80^{\circ} \mathrm{C}$ until assayed. ELISA for both IL-6 and IL-8 was carried out using commercial kits purchased from Bio-source International (San Diego, California, USA). The detection limit was $1.2 \mathrm{pg} / \mathrm{mL}$ for IL-6 and $0.5 \mathrm{pg} / \mathrm{mL}$ for IL-8. Samples below the limit of detection were considered negative.

\section{Statistical Analysis}

Statistical analysis was performed using SPSS version 25.0. Chi-square test, Fisher Exact test, Student $t$-test and Alternate Welch's test were used as appropriate. P values $<=0.05$ indicates statistical significance.

\section{Results}

A total of 43 children with their first urinary tract infection were included. The mean age at presentation was $46.0 \pm 35.7$ months (range: 2 months to 11 years). Acute pyelonephritis (AP) was diagnosed in 22 patients, and acute cystitis was diagnosed in 21 patients. The mean age of patients with acute pyelonephritis was $45.2 \pm 28.5$ months compared to a mean age of $46.8 \pm 42.6$ months among cystitis patients (CYS).

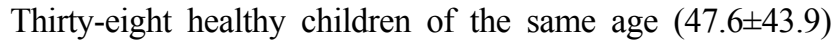
and ethnic backgrounds were included as controls (Table 1).

Some of the important clinical and biochemical parameters in the AP and CYS groups are shown in Table 1. The mean $\mathrm{WBC}$ was significantly higher in the AP group $\left(16.72 \pm 7.32 \times 10^{9}\right)$ than in the CYS group $\left(7.90 \pm 2.77 \times 10^{9}\right)$.

The mean CRP and ESR levels were significantly higher in the AP group than in the CYS group.

Table 2 summarizes the common bacterial pathogens isolated in urine cultures of the patients. Escherichia coli (E. coli) was the most common causative pathogen involved in UTI in both infected groups.

Serum and urine Il- 6 and IL- 8 positivity rates during the acute phase are represented in Table 3. There were no

Table I Summary of the Clinical and Biochemical Parameters of Patients with Acute Pyelonephritis and Cystitis Compared to Controls

\begin{tabular}{|c|c|c|c|c|c|}
\hline Parameter & (I) Acute Pyelonephritis $n=22$ & (2) Cystitis $n=2 I$ & (3) Control $n=38$ & & $P$ value \\
\hline Mean age (months) & $45.2 \pm 28.5$ & $46.8 \pm 42.6$ & $47.6 \pm 43.9$ & $\begin{array}{l}\text { I vs } 2 \\
\text { I vs } 3 \\
2 \text { vs } 3\end{array}$ & $\begin{array}{l}0.89 \\
0.79 \\
0.95\end{array}$ \\
\hline Male: Female ratio & $\mathrm{I}: 4$ & $\mathrm{I}: 4.2$ & $\mathrm{I}: 4.4$ & - & - \\
\hline Mean WBC count $\left(\times 10^{9}\right)$ & $16.72 \pm 7.32$ & $7.90 \pm 2.77$ & $6.8 \pm 2.4$ & $\begin{array}{l}\text { I vs } 2 \\
\text { I vs } 3 \\
2 \text { vs } 3\end{array}$ & $\begin{array}{l}<0.000 I^{*} \\
<0.000 I^{*} \\
0.12\end{array}$ \\
\hline Mean ESR $(\mathrm{mm} / \mathrm{hr})$ & $55.5 \pm 31.05$ & $13.48 \pm 8.48$ & $10.2 \pm 5.1$ & $\begin{array}{l}\text { I vs } 2 \\
\text { I vs } 3 \\
2 \text { vs } 3\end{array}$ & $\begin{array}{l}<0.0001 * \\
<0.0001 * \\
0.12\end{array}$ \\
\hline Mean CRP (mg/mL) & $10.85 \pm 2.77$ & $0.18 \pm 0.1$ & $0.15 \pm 0.3$ & $\begin{array}{l}\text { I vs } 2 \\
\text { I vs } 3 \\
2 \text { vs } 3\end{array}$ & $\begin{array}{l}<0.000 I^{*} \\
<0.000 I^{*} \\
0.58\end{array}$ \\
\hline Serum Creatinine (micromol/L) & $66 \pm 44$ & $52 \pm 39$ & $48 \pm 22$ & $\begin{array}{l}\text { I vs } 2 \\
\text { I vs } 3 \\
2 \text { vs } 3\end{array}$ & $\begin{array}{l}0.20 \\
0.08 \\
0.67\end{array}$ \\
\hline${ }^{A}$ Positive I ${ }^{S T}$ DMSA n (\%) & $18 / 22(82 \%)$ & $0 / 21(0)$ & - & & $<0.0001 *$ \\
\hline${ }^{\mathrm{B}}$ Renal scarring on 2nd DMSA $\mathrm{n}(\%)$ & $8 / 18(44 \%)$ & $0 / 21(0)$ & - & & $<0.001 *$ \\
\hline Abnormal ultrasound $\mathrm{n}(\%)$ & $8 / 22(36 \%)$ & $|/ 2|(4 \%)$ & - & & $0.02 *$ \\
\hline
\end{tabular}

Notes: ${ }^{A}$ During acute infection; ${ }^{B}$ Six-months after recovery; ${ }^{*}$ Significant $P$ value. 
Table 2 Bacterial Pathogens Cultured from the Urine of Patients with Acute Pyelonephritis and Cystitis

\begin{tabular}{|l|l|l|}
\hline $\begin{array}{l}\text { Urine Culture } \\
\text { Pathogens }\end{array}$ & $\begin{array}{l}\text { Acute Pyelonephritis } \\
\mathbf{n = 2 2} \mathbf{N}(\%)\end{array}$ & $\begin{array}{l}\text { Cystitis } \\
\mathbf{n = 2} \text { I N(\%) }\end{array}$ \\
\hline Escherichia coli & $\mathrm{I}(86 \%)$ & $\mathrm{I} 6(76 \%)$ \\
Pseudomonas aeruginosa & $\mathrm{I}(4.5 \%)$ & $\mathrm{I}(4.7 \%)$ \\
Enterococci & $\mathrm{I}(4.5 \%)$ & 0 \\
Proteus species & $\mathrm{I}(4.5 \%)$ & $3(14 \%)$ \\
Klebsiella species & 0 & $\mathrm{I}(4.7 \%)$ \\
\hline
\end{tabular}

significant differences in the rate of positivity between the 2 patient groups. In this study, any result that is below the limit of detection of the kit used is referred to as negative.

\section{Urinary IL-6 Levels (Figure IA)}

IL-6 was detected in $42 \%(18 / 43)$ of patients compared to $18 \%$ of controls.

The positivity rate among the AP group was 53\% compared to $35 \%$ among the CYS group (Table 3 ).

The mean IL-6 level was $16.9 \mathrm{pg} / \mathrm{mL}$ in the AP group compared to $14.8 \mathrm{pg} / \mathrm{mL}$ in the controls $(\mathrm{p}=0.27)$. The mean level of IL-6 in CYS patients was $17.8 \mathrm{pg} / \mathrm{mL}$, which was significantly higher than the control group $(p=0.03)$. Nevertheless, the difference between the means of the AP and CYS groups was not statistically significant $(\mathrm{p}=0.69)$.

Convalescent urine samples collected 8 weeks postinfection were positive for IL-6 in $31 \%$ of the AP group compared to $43 \%$ of the CYS group. The mean IL-6 level in the AP group was $12.1 \mathrm{pg} / \mathrm{mL}$ compared to $11.5 \mathrm{pg} / \mathrm{mL}$ in the cystitis group, which was not statistically significant.
Figure 1-A illustrates the different urinary IL6 levels in the 3 groups during the acute and convalescent phases.

\section{Serum IL-6 Levels (Figure IB)}

IL-6 was detected during the acute phase in $35 \%$ of the AP group compared to $26 \%$ of CYS patients and $14 \%$ of controls (Table 3). The mean IL-6 level in the AP group was $19.4 \mathrm{pg} /$ $\mathrm{mL}$ compared to $19.5 \mathrm{pg} / \mathrm{mL}$ in CYS patients and $15.0 \mathrm{pg} /$ $\mathrm{mL}$ among controls. The difference was statistically significant between AP and controls $(\mathrm{p}=0.02)$ as well as between the CYS group and controls $(\mathrm{p}=0.005)$. However, the difference was not significant between the AP and CYS groups.

During the convalescent phase, there was no significant difference in serum IL-6 between the AP and CYS groups, as shown in Figure 1B.

\section{Urinary IL-8 (Figure 2A)}

IL-8 was detected in the acute samples of $84 \%(36 / 43)$ of patients with urinary tract infection compared to $55 \%$ of controls. The positivity rate among the AP group was $82 \%$ compared to $85 \%$ among the cystitis group (Table 3 ). The mean urinary IL-8 level was $206.5 \mathrm{pg} / \mathrm{mL}$ in the AP group compared to $89.4 \mathrm{pg} / \mathrm{mL}$ in the controls $(\mathrm{p}=0.05)$.

The mean level of IL-8 in cystitis patients was 291.8 $\mathrm{pg} / \mathrm{mL}$, which was significantly higher than the control group ( $p=0.02$ ). Nevertheless, the difference between the means of AP and the cystitis groups was not statistically significant $(\mathrm{p}=0.36)$.

Convalescent urine samples collected 8 weeks postinfection were positive for IL- 8 in $23 \%$ of the AP group compared to $28.5 \%$ of the cystitis group. The mean IL-8

Table 3 IL-6 and IL-8 Positivity Rates During the Acute Phase of UTI Expressed as Percentages

\begin{tabular}{|c|c|c|c|c|}
\hline Positivity Rate \% & (I) Cystitis $n=2 I$ & (2) Acute Pyelonephritis $n=22$ & (3) Controls $n=38$ & OR (95\% CI) $P$ value \\
\hline Urinary IL-6 & $35 \%$ & $53 \%$ & $18 \%$ & $\begin{array}{l}\text { I vs } 20.42(0.12-I .43) 0.22 \\
\text { I vs } 32.2 \text { I }(0.65-7.52) 0.22 \\
2 \text { vs } 35.3 \text { I }(1.64-17.19)<0.0 \text { I* }\end{array}$ \\
\hline Serum IL-6 & $26 \%$ & $35 \%$ & $14 \%$ & $\begin{array}{l}\text { I vs } 20.55(0.15-2.06) 0.5 \text { I } \\
\text { I vs } 32.06(0.52-8.17) 0.3 \text { I } \\
2 \text { vs } 33.77(1.05-13.57) 0.05^{*}\end{array}$ \\
\hline Urinary IL-8 & $85 \%$ & $82 \%$ & $55 \%$ & $\begin{array}{l}\text { I vs } 2 \text { I. } 33(0.26-6.83) \text { I.00 } \\
\text { I vs } 34.85(\text { I.22-19.30) } 0.02 * \\
2 \text { vs } 33.64(I .04-12.82) 0.05^{*}\end{array}$ \\
\hline Serum IL-8 & $9.5 \%$ & $18 \%$ & $18 \%$ & 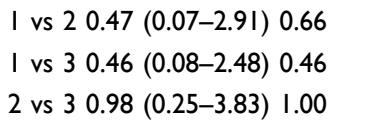 \\
\hline
\end{tabular}

Note: *Significant $\mathrm{P}$ value. 
A

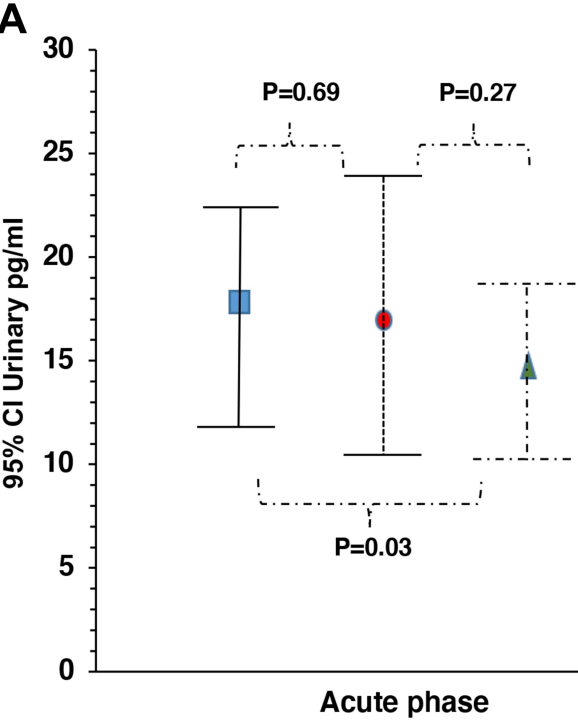

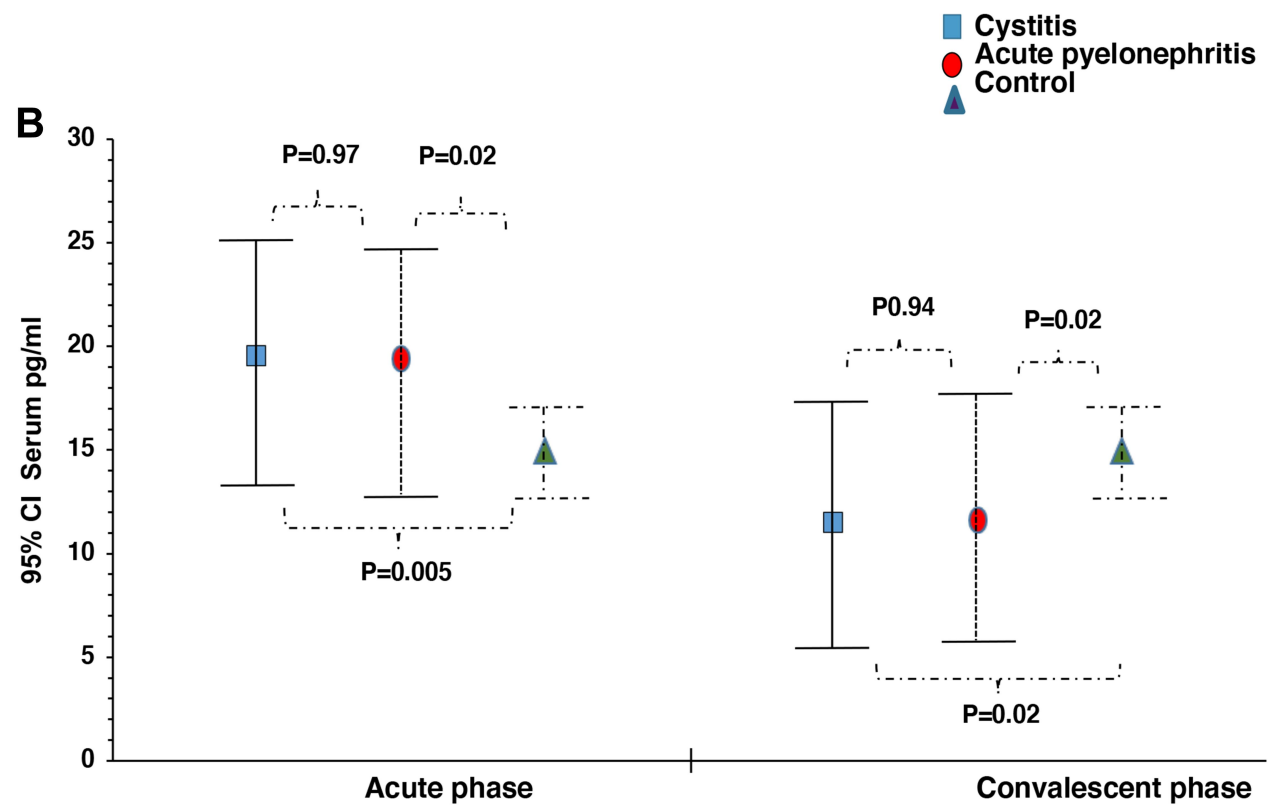

Cystits

Acute pyelonephritis

Control

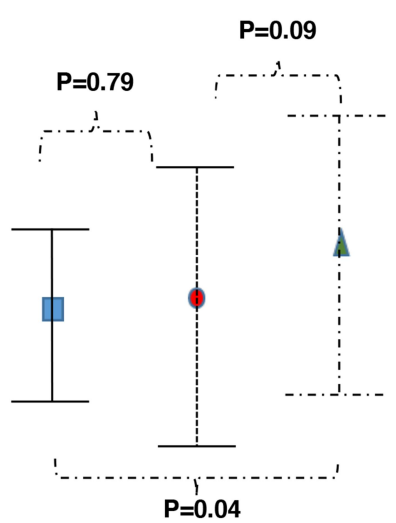

Convalescent phase

Cystitis

Acute pyelonephritis

Control

Figure I Urinary and serum IL-6 levels. (A) Urinary IL-6 levels during acute and convalescent phases of UTI. In the acute phase, urinary IL-6 ELISA results showed significantly higher levels in the cystitis group compared to controls, while no significant difference was detected between the 2 patient groups. In the convalescent phase, no significant difference was reported between the 3 groups. (B) Serum IL-6 levels during acute and convalescent phases of UTI. Serum IL-6 ELISA results showing that serum IL-6 is significantly higher in the patient groups compared to controls, however, no difference was detected between the patients groups, during both acute and convalescent phases of UTI.

level in the AP group was $60.77 \mathrm{pg} / \mathrm{mL}$ compared to 70.8 $\mathrm{pg} / \mathrm{mL}$ in the cystitis group, which was not significantly different.

\section{Serum IL-8 (Figure 2B)}

IL-8 was detected during the acute phase in $18 \%$ of the AP group compared to $9.5 \%$ of cystitis patients and $18 \%$ of controls (Table 3). The mean IL-8 level in the AP group was $28.8 \mathrm{pg} / \mathrm{mL}$ vs $18.5 \mathrm{pg} / \mathrm{mL}$ in cystitis patients and
$19.02 \mathrm{pg} / \mathrm{mL}$ among controls. The difference was not statistically significant between any of the 3 groups.

In convalescent samples, IL- 8 was detected in $23 \%$ of the AP group and in $24 \%$ of the cystitis patients. The difference in the means of the two groups was not significant.

\section{Discussion}

In the present study, we demonstrated that patients with a UTI have elevated levels of IL-6 and IL-8 compared to 


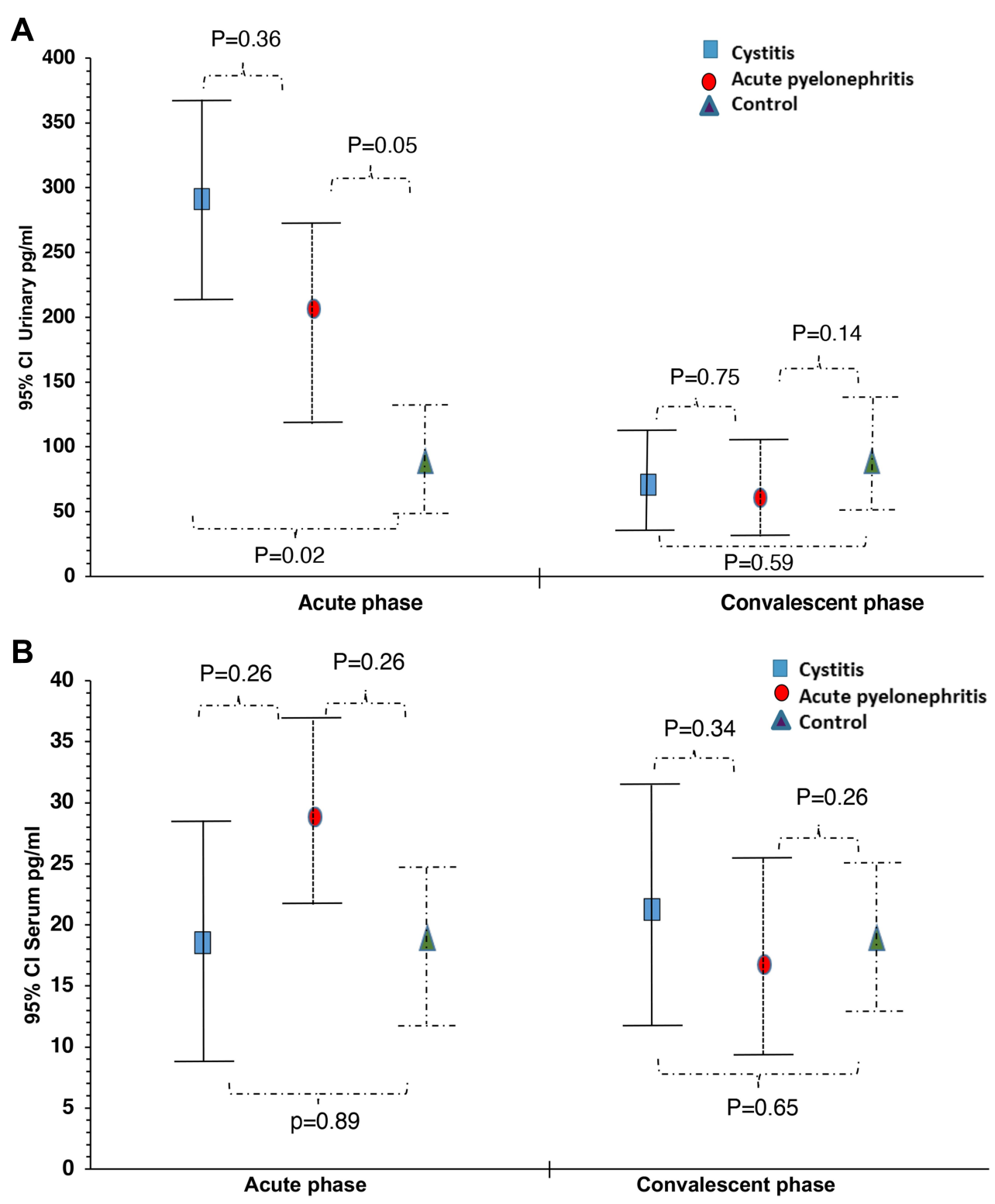

Figure 2 Urinary and serum IL-8 levels. (A) Urinary IL-8 levels during acute and convalescent phases of UTI. During both the acute and the convalescent phases, urinary IL8 ELISA results showed that it was higher in patients groups compared to controls with no significant difference between the AP and Cys groups. (B) Serum IL-8 levels during acute and convalescent phases of UTI. ELISA results of the serum IL- 8 showed no significant difference between the 3 groups during both the acute and the convalescent phases of UTI.

healthy controls during acute infection, which supports that these cytokines have a pivotal role in the pathogenesis and clinical expression of UTI. However, the levels were not significantly different between upper and lower UTIs.

Systemic release of various mediators contributes to the clinical expression of acute pyelonephritis while in lower UTIs, cytokines are secreted mainly in the urine, explaining the absence of systemic toxicity symptoms in acute cystitis. ${ }^{1}$ Yet, We could not detect a difference in the serum concentrations of IL- 6 and IL- 8 between the 2 groups in our sample. It has been reported that host response to the presence of bacteria in the urinary tract might be genetically determined. It has been suggested that the genetic polymorphisms of cytokines may influence the type of host response during an infection. ${ }^{1}$ People who are lower cytokine responders may not have systemic symptoms despite the presence of bacteria in their urine. ${ }^{1,11-13}$

Other possible explanations include the fact that in the present study, the serum samples were collected very early in the disease process. Other mediators should be evaluated too. 
Many studies have reported elevated levels of IL- 6 and IL-8 in the serum and urine of patients with acute renal infection as well as in renal scarring. ${ }^{5-10}$ Whether their levels early in the disease point towards the site of infection in the urinary tract is elusive.

Krzemien et $\mathrm{al}^{1}$ reported that the levels of urinary IL-6 and IL-8 were significantly higher in infants with febrile UTI than in patients with afebrile UTI or asymptomatic bacteriuria. Similar to our findings, the urinary levels of both IL-6 and IL-8 did not differentiate upper from lower infection in infants with febrile UTI. ${ }^{1}$ Similarly, Benson et $\mathrm{al},{ }^{8}$ who evaluated 61 children with their first febrile UTI and 39 children with asymptomatic bacteriuria, demonstrated that the levels of serum and urine IL- 6 and urine IL-8 were higher in children with febrile UTI. In addition, serum IL-6 levels in adult patients with acute pyelonephritis were higher than in patients with asymptomatic bacteriuria as reported by a study by Hedges et al. ${ }^{14}$

It has been suggested that the IL-6 response varies with the severity of infection ${ }^{1,8,15-17}$ as well as renal scarring. ${ }^{1,8,9}$

Elevated IL-6 has been associated with increased hospital mortality rates in ICU patients with acute kidney injury. ${ }^{15}$ Mizutani et $\mathrm{al}^{16}$ have shown that serum IL-6 is significantly higher in patients with acute focal bacterial nephritis, a severe form of upper UTI showing an inflammatory mass but no abscess, than in acute pyelonephritis. Patients with the former condition are at higher risk of treatment failure and renal scarring.

Gokce et $\mathrm{al}^{3}$ demonstrated a significant correlation between the presence of vesicoureteric reflux and urinary IL-6 levels, which might support the suggestion that elevated IL-6 might predict acute pyelonephritis. ${ }^{3}$

Based on the aforementioned studies' findings, it is implied that IL-6 is a strong candidate to be one of the major biomarkers for acute pyelonephritis, as it has been shown to be involved in the more severe forms of renal pathology. However, the results of previous studies are inconclusive.

The lack of a significant difference in IL-6 levels between the patients with acute cystitis and acute pyelonephritis in the present study might be attributed to early sample collection, small number of patients or young age groups.

During the convalescent phase, we reported that IL-6 levels were significantly lower in patients than in controls. Both IL-6 and IL-8 are present in the urine of healthy subjects. $^{3}$ The significantly lower IL-6 in the convalescent phase, could be attributed to the modulation of the local cytokine response to UTI by anti-inflammatory agents, used in the treatment, as well as early sample collection. However, more studies are warranted.

IL-8 is a neutrophil chemoattractant. The levels in our study were higher in the infection group than in the control group; however, the levels were not significantly different between acute cystitis and pyelonephritis. Similar findings have been reported by others. ${ }^{1,3,8}$ In addition, the urinary IL-8 levels in our study were higher than the serum levels, which might be explained by the fact that IL-8 acts locally to recruit neutrophils causing pyuria.

It has been demonstrated that urinary IL-8 has a high negative predictive value in UTI; therefore, it might be useful as a screening tool. ${ }^{18}$ IL-8 was increased in $92 \%$ of UTIs, independent of the causative microorganisms, with an average value of $627 \mathrm{pg} / \mathrm{mL}{ }^{18}$ Similarly, IL-8 was a better marker of UTI than IL-6, as IL-8 increased on the day of diagnosis of the infection. ${ }^{19}$ It has been demonstrated that elevated levels of IL-8 in infants with UTI were associated with increased risk of renal scarring in the future. ${ }^{20}$

In our study, urinary IL-6 and IL-8 levels were higher in the cystitis group than in the AP group, though it was not statistically significant. Part of this difference might be attributed to the fact that cytokines are filtered at the glomerulus and then endocytosed and metabolized by the proximal tubule for excretion. Filtration and excretion of the cytokines can be compromised in AP, so they ended up with less cytokines filtered in the urine. ${ }^{21}$

We have demonstrated a high positivity rate of urine cytokines during the convalescent phase. This might reflect a slower clearance or prolonged excretion. In addition, samples were collected 8 weeks post recovery, which might be too early to clear all the effects of the infection and its inflammatory responses.

In our study, we included children with confirmed acute pyelonephritis by DMSA scan. We were able to collect samples early in the infection process. Both urinary and serum cytokine levels were evaluated.

Limitations to our study include difficulty in recruiting older pediatric patients with acute pyelonephritis to eliminate the age discrepancy between the acute pyelonephritis and cystitis groups. Many patients were lost during followup, so they had to be excluded from the study, which is why we had a small number of patients. The early collection of urine samples after recovery might limit the ability to detect significant differences. Serial sample collections up to more than 6 months in the absence of recurrent 
infection might be more useful. It would prudent to include the results of evaluation of our patients for vesicoureteric reflux and renal scarring in follow-up.

\section{Conclusion}

Urinary IL-6 and IL-8 assays in the acute phase of urinary tract infection might be useful bioindicators of UTI but did not differentiate upper from lower UTI in our study. Nonetheless, their role in differentiating the site of UTI needs to be elucidated.

\section{Abbreviations}

AP, acute pyelonephritis; CRP, C-reactive protein; Cys, cystitis; DMSA scan, 99 Tc-dimercaptosuccinic acid scintigraphy scan; ELISA, enzyme-linked immunosorbent assay; ESR, erythrocyte sedimentation rate; IL, interleukin; UTI, urinary tract infection.

\section{Data Sharing Statement}

The authors opt to not share the data.

\section{Ethics Approval}

The study was approved by the Health Sciences Center's (HSC) Ethical Committee for the protection of human subjects in research, Kuwait University. The Study was conducted in accordance with the Declaration of Helsinki.

\section{Consent to Participate}

Informed consent was obtained from caregivers of patients and controls.

\section{Acknowledgment}

The authors would like to acknowledge Ms. Asiya Tasneem Ibrahim for her help with the statistical analysis.

\section{Author Contributions}

All authors made a significant contribution to the work reported, whether that is in the conception, study design, execution, acquisition of data, analysis and interpretation, or in all these areas; took part in drafting, revising or critically reviewing the article; gave final approval of the version to be published; have agreed on the journal to which the article has been submitted; and agree to be accountable for all aspects of the work.

\section{Funding}

There is no funding to report.

\section{Disclosure}

The authors have no conflicts of interest to declare for this work.

\section{References}

1. Krzemień G, Szmigielska A, Turczyn A, Pańczyk-Tomaszewska M. Urine interleukin-6, interleukin- 8 and transforming growth factor $\beta 1$ in infants with urinary tract infection and asymptomatic bacteriuria. Cent Eur J Immunol. 2016;41(3):260-267. doi:10.5114/ceji.2016.63125

2. Tramma D, Hatzistylianou M, Gerasimou G, Lafazanis V. Interleukin-6 and interleukin-8 levels in the urine of children with renal scarring. Pediatr Nephrol. 2012;27(9):1525-1530. doi:10.1007/ s00467-012-2156-2

3. Gokce I, Alpay H, Biyikli N, Unluguzel G, Dede F, Topuzoglu A. Urinary levels of interleukin-6 and interleukin- 8 in patients with vesicoureteral reflux and renal parenchymal scar. Pediatr Nephrol. 2010;25(5):905-912. doi:10.1007/s00467-009-1396-2

4. Su H, Lei CT, Zhang C. Interleukin-6 signaling pathway and its role in kidney disease: an update. Front Immunol. 2017;8:405. doi:10.33 89/fimmu.2017.00405

5. Roilides E, Papachristou F, Gioulekas E, et al. Increased urine interleukin-6 concentrations correlate with pyelonephritic changes on $99 \mathrm{mTc}$-dimercaptosuccinic acid scans in neonates with urinary tract infections. J Infect Dis. 1999;180(3):904-907. doi:10.1086/314960

6. Sheu JN, Chen MC, Lue KH, et al. Serum and urine levels of interleukin-6 and interleukin-8 in children with acute pyelonephritis. Cytokine. 2006;36(5-6):276-282. doi:10.1016/j.cyto.2007.02.006

7. Galanakis E, Bitsori M, Dimitriou H, Giannakopoulou C, Karkavitsas NS, Kalmanti M. Urine interleukin-8 as a marker of vesicoureteral reflux in infants. Pediatrics. 2006;117(5):e863-7. doi:10.1542/peds.2005-2051

8. Benson M, Jodal U, Agace W, et al. Interleukin (IL)-6 and IL-8 in children with febrile urinary tract infection and asymptomatic bacteriuria. J Infect Dis. 1996;174(5):1080-1084. doi:10.1093/ infdis/174.5.1080

9. Rodríguez LM, Robles B, Marugán JM, Suárez A, García Ruiz de Morales JM. Do serum C-reactive protein and interleukin-6 predict kidney scarring after urinary tract infection? Indian $J$ Pediatr. 2013;80(12):1002-1006. doi:10.1007/s12098-013-1045-4

10. Rodríguez LM, Robles B, Marugán JM, Suárez A, Santos F. Urinary interleukin-6 is useful in distinguishing between upper and lower urinary tract infections. Pediatr Nephrol. 2008;23(3):429-433. doi:10.1007/s00467-007-0670-4

11. Ragnarsdóttir B, Svanborg C. Susceptibility to acute pyelonephritis or asymptomatic bacteriuria: host-pathogen interaction in urinary tract infections. Pediatr Nephrol. 2012;27(11):2017-2029. doi:10.10 07/s00467-011-2089-1

12. Yun KW, Kim HY, Park HK, Kim W, Lim IS. Virulence factors of uropathogenic Escherichia coli of urinary tract infections and asymptomatic bacteriuria in children. J Microbiol Immunol Infect. 2014;47 (6):455-461. doi:10.1016/j.jmii.2013.07.010

13. Spasojević-Dimitrijeva B, Zivković M, Stanković A, Stojković L, Kostić M. The IL-6-174G/C polymorphism and renal scarring in children with first acute pyelonephritis. Pediatr Nephrol. 2010;25 (10):2099-2106. doi:10.1007/s00467-010-1587-x

14. Hedges S, Stenqvist K, Lidin-Janson G, Martinell J, Sandberg T, Svanborg C. Comparison of urine and serum concentrations of interleukin-6 in women with acute pyelonephritis or asymptomatic bacteriuria. $J$ Infect Dis. 1992;166(3):653-656. doi:10.1093/infdis/ 166.3.653

15. Shimazui T, Nakada TA, Tateishi Y, Oshima T, Aizimu T, Oda S. Association between serum levels of interleukin-6 on ICU admission and subsequent outcomes in critically ill patients with acute kidney injury. BMC Nephrol. 2019;20(1):74. doi:10.1186/s12882-019-1265-6 
16. Mizutani M, Hasegawa S, Matsushige T, et al. Distinctive inflammatory profile between acute focal bacterial nephritis and acute pyelonephriritis in children. Cytokine. 2017;99:24-29. doi:10.1016/j.cyto. 2017.06.012

17. Gürgöze MK, Akarsu S, Yilmaz E, et al. Proinflammatory cytokines and procalcitonin in children with acute pyelonephritis. Pediatr Nephrol. 2005;20(10):1445-1448. doi:10.1007/s00467-005-1941-6

18. Oregioni O, Delaunay $\mathrm{P}$, Bruna $\mathrm{P}$, et al. urinary interleukin- 8 is elevated in urinary tract infections independently of the causative germs. Cytokine. 2005;31(6):415-418. doi:10.1016/j.cyto.2005.06. 009
19. Olszyna DP, Vermeulen H, Baan AH, et al. Urine interleukin-8 is a marker for urinary tract infection in postoperative patients. Infection. 2001;29(5):274-277. doi:10.1007/s15010-001-1157-Z

20. Sheu JN, Chen SM, Meng MH, Leu KH. The role of serum and urine interleukin-8 in acute pyelonephritis and subsequent renal scarring in children. Pediatr Infect Dis J. 2009;28(10):885-890. doi:10.1097/ INF.0b013e3181a39e23

21. Dennen P, Altmann C, Kaufman J, et al. Urine interleukin-6 is an early biomarker of acute kidney injury in children undergoing cardiac surgery. Crit Care. 2010;14(5):R181. doi:10.1186/cc9289

\section{Publish your work in this journal}

The Journal of Inflammation Research is an international, peerreviewed open-access journal that welcomes laboratory and clinical findings on the molecular basis, cell biology and pharmacology of inflammation including original research, reviews, symposium reports, hypothesis formation and commentaries on: acute/chronic inflammation; mediators of inflammation; cellular processes; molecular mechanisms; pharmacology and novel anti-inflammatory drugs; clinical conditions involving inflammation. The manuscript management system is completely online and includes a very quick and fair peerreview system. Visit http://www.dovepress.com/testimonials.php to read real quotes from published authors.

Submit your manuscript here: https://www.dovepress.com/journal-of-inflammation-research-journal 